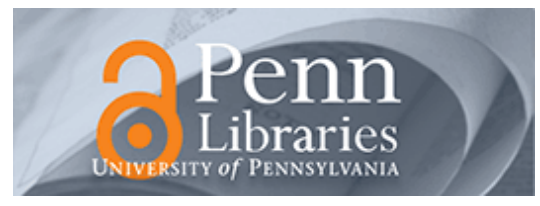

University of Pennsylvania

ScholarlyCommons

Real Estate Papers

Wharton Faculty Research

2008

\title{
What Is a Tree Worth? Green-City Strategies, Signaling and Housing Prices
}

Susan M. Wachter

University of Pennsylvania

Grace Wong

University of Pennsylvania

Follow this and additional works at: https://repository.upenn.edu/real-estate_papers

Part of the Economics Commons, and the Real Estate Commons

Recommended Citation

Wachter, S. M., \& Wong, G. (2008). What Is a Tree Worth? Green-City Strategies, Signaling and Housing

Prices. Real Estate Economics, 36 (2), 213-239. http://dx.doi.org/10.1111/j.1540-6229.2008.00212.x

This paper is posted at ScholarlyCommons. https://repository.upenn.edu/real-estate_papers/46

For more information, please contact repository@pobox.upenn.edu. 


\title{
What Is a Tree Worth? Green-City Strategies, Signaling and Housing Prices
}

\author{
Abstract \\ We investigate the correlation between curbside tree plantings and housing price movements in \\ Philadelphia from 1998 to 2003, comparing two programs, one by the Philadelphia Horticultural Society \\ (PHS) that requires block-group effort that focuses on low-income neighborhoods and the other by the \\ Fairmount Park Commission that is individual-based without specific target areas. A 7 to $11 \%$ price \\ differential is identified within 4,000 feet of the Fairmount tree plantings. We argue that this is largely \\ driven by either social capital creation or a signaling mechanism, on top of an intrinsic tree value (around \\ $2 \%$ ). Findings using the PHS tree program suggest that development of social capital or environmentally \\ conscious behavior might be a less important channel. Any positive changes brought by the PHS tree \\ plantings were not detected with sufficient statistical power. \\ Disciplines \\ Economics | Real Estate | Social and Behavioral Sciences
}




\title{
What is a tree worth? \\ Green-city Strategies and Housing Prices
}

\author{
Susan Wachter \\ The Wharton School \\ and \\ Grace Wong \\ The Wharton School
}




\begin{abstract}
We investigate the correlation between curb-side tree plantings and housing price movements in Philadelphia from 1998 to 2003, comparing two programs, one by the Philadelphia Horticultural Society that requires block-group effort that focuses on lowincome neighbourhoods and the other by the Fairmount Park Commission that is individual-based without specific target areas. A 7 to 11 percent price differential is identified within $4000 \mathrm{ft}$ of the Fairmount tree plantings. We argue that this is largely driven by either social capital creation or a signaling mechanism, on the top of an intrinsic tree value (around 2 percent). Findings using the PHS tree program suggest that development of social capital or environmentally-conscious behavior might be a less important channel. Any positive changes brought by the PHS tree plantings were not detected with sufficient statistical power.
\end{abstract}




\section{Introduction}

Greening projects are generally viewed as a positive development in the neighborhood. Of all 32 elected mayors in the largest 100 metropolitan cities in 2005,15 of them mentioned a greening program in their electoral platform. It has been argued that environmental interventions such as tree planting programs that make environmentally sound behaviors easier to engage in and their economic returns more apparent are more effective than public education efforts that focus on changing attitudes. (Summit 1997) While there has been some quantitative analysis on the value of trees in the urban planning literature (Anderson 1985, 1988), complemented by survey evidence that inner city residents factor in the availability of trees in their residence location decisions (Getz et al. 1982), little has been said about the direct causal impact of greening programs.

The aim of this paper is to shed light on the impact of tree plantings on the perceived quality of life and thus the first half of the cost-benefit analysis. Specifically, we test the correlation of tree plantings with housing sale prices, interpreting the price differentials directly attributable to the plantings as compensating differentials in the housing market. To disentangle the impact of tree planting from other confounding factors, we use the Geographic Information System to map out positions of all new tree plantings and housing sales in Philadelphia between 1998 and 2003, for a comparative study by both distances to tree plantings and by when the transaction took place relative to the tree planting. Also, a comparison is made between two nonprofit tree planting programs, organized by the Fairmount Park Commission and the Philadelphia Horticultural Society (Fairmount and PHS programs henceforth), with contrasting aims 
and approaches (Section 2). To control for time effects and other city-wide unobservables in housing price movements, we perform a within-neighborhood (census tract) analysis. This means any city-wide housing price impact due to tree plantings will not be captured in our estimation.

There are four main reasons why one might expect a price change correlated to tree planting events in proximity to the parcel. First, the value of the trees should be reflected in the post-tree-planting sales price. Second, any increase in social capital or environmentally protective behavior resulted from the tree plantings will be also capitalized in prices. Third, it is conceivable that home sellers use tree plantings to signal otherwise unobservable characteristics of the neighborhood, such as social capital, to potential homebuyers. Fourth, the tree planting might proxy for qualities of the house or neighborhood that are unobserved by the econometrician but capitalized in home prices. These omitted variables might or might not have a direct relationship with tree plantings. Unlike the first three mechanisms, the omitted variable bias can be in either direction. ${ }^{i}$

We attempt to disentangle these explanations by carefully constructing the treatment and control groups. Primarily we focus on the tree plantings by the Fairmount Park Commission, which responds to requests of tree by individual Philadelphian city residents. A comparison between parcels sold within 1000ft of a between-sales Fairmount planting with other sales reveals a statistically significant planting-related premium between 7 to 11 percent. Two percentage points of this premium can be attributed to the value of the trees. We argue that the omitted variable bias is around 2 percent, by 
comparing parcels along the propensity of ever getting a tree. There is evidence that the identified price differential is significant and stable within $4000 \mathrm{ft}$ of the planting.

In order to shed some light on the importance of social capital creation versus that of signaling, we also explore data of another tree program in Philadelphia. The green city program under the Philadelphia Horticultural Society (PHS) requires coordinated effort by residents on the same block. If creation of social capital were the main driver behind the positive price change related to the Fairmount Park Commission tree plantings and if unobserved characteristics play a relatively small role, then we would expect a significant and positive price change related to a PHS planting, of a magnitude larger than what is found using Fairmount trees. On the other hand, the aim of the PHS program is to create a better living environment for struggling neighborhoods, so the baseline price difference unrelated to the tree plantings - the selection bias - is expected to be strongly negative. The signaling effect can point either way relative to that of Fairmount trees. When compared to all other housing sales in the city, houses within 1000ft of a PHS planting were sold at a discount. No strong evidence is found for positive changes related to PHS plantings, pointing to small effects, if any, brought by the plantings. One possibility is a lagged response to signaling in less affluent neighborhoods, which is not studied in this paper due to data limitations. Similarly, the differential impact of the tree planting programs by various initial conditions of the neighborhoods - income, education and neighborhood coercion come to mind - is not covered by this study. 


\section{Tree Planting Programs in Philadelphia}

This paper studies the two different programs through which Philadelphia residents can apply for street (curb-side) tree plantings. For various reasons, including potential noise production and damage of underground utility lines, residents are not allowed to plan street trees on their own.

The Fairmount Park Commission tree planting program allows approximately 900 individual homeowners throughout the city of Philadelphia to apply for street trees annually. There is generally a year long wait between the receipt of the application and the tree planting, not including a waiting list for initial processing of application. With the support of the city's Capital Program, trees are provided completely free of charge after approval and are distributed without preference throughout Philadelphia.

The Pennsylvania Horticultural Society (PHS) is also the proprietor of a street tree planting program. Starting in 1995, PHS collaboratively organized with the New Kensington Community Development Corporation (NKCDC) in an initiative to manage vacant land from the neighborhood level. Street tree planting, community gardens, are a few of the specific facets of this program.

The street tree programs facilitated by the Fairmont Park Commission and Pennsylvania Horticultural Society cater equally to the residents of Philadelphia but promote different levels of community involvement. Although the Fairmount tree program entails a delayed and competitive application process, all aspects of tree planting 
including expense are managed at the organizational level. The PHS program is in stark contrast to this system where individuals must cover (a nominal) part of the expenses and the majority of planting responsibility. Further, the receipt of a PHS tree involves training and commitment as a neighborhood Tree Tender.

\section{Data}

The housing price dataset at hand has been filtered in order to include only armslength transactions. All transactions with the price of $\$ 500$ or below were dropped, as were transactions where the seller and buyer was the same person. Moreover, residential properties outside Philadelphia (property zip code starting with "191") or those sold by the government, HUD or the sheriff were discarded. 1,151 Fairmount tree plantings and 1,668 PHS tree plantings are merged by location to the housing sales data set.

Table 1 shows the summary statistics for the full sample, and those housing sales with a Fairmount or PHS tree planting within 100/ 500 feet between sales. The percentage of parcel sales that took place in proximity of a tree planting is shown in Table 2 by the relative timing of the sales and the plantings. Relative to all houses being sold, parcels situated within 100/ 500 feet within either type of tree plantings between sales are smaller in size. While houses near PHS plantings are more likely to be adjacent to vacant lots, the opposite is true for those near Fairmount plantings. The same difference is also reflected by the sales price from the previous sale transaction. A comparison of the differences between current and previous sales prices, it is evident that Fairmount plantings took place in fast-growing neighborhoods while PHS plantings 
typically occurred in areas with below-average price growth. This suggests systematic pre-tree planting differences that need to be controlled for in the price analysis.

\section{Empirical Evidence - Fairmount Plantings}

To investigate price movements correlated with tree plantings, the following regression is performed:

$P_{i t}=\alpha+\mu P_{i t-1}+\beta$ Tree $_{i t}+\gamma H_{i}+C_{i}+\xi G_{a p} i t+\sigma\left(P_{i t-1} * G a p_{i t}\right)+$ Time $_{t}+\varepsilon_{i t},(1)$

where $P_{i t}$ and $P_{i t-l}$ are the real sales price and the previous real sales price in $\operatorname{logs}, \alpha$ a constant term, $H_{i}$ a group of housing characteristics, $C_{i}$ the census-tract fixed effects, $G a p_{i t}$ a measure of time lag between the sales and the previous sales and $\varepsilon_{i t}$ an error term clustered at the census-tract level. ${ }^{\mathrm{ii}}$ Time $_{i t}$ stands for a group of time controls: year fixed effects, quarter fixed effects and a set of census tract-specific linear time trends. By controlling for census-tract fixed effects, all comparisons are within tracts. Any timeinvariant factors are absorbed by lagged price $\mathrm{P}_{\mathrm{it}-1}$. By regressing on sales prices while controlling for lagged price and the gap between sales, instead of regression on a rate of price change, more flexibility in functional form is allowed for.

Table 3 makes a simple comparison between sales of parcels with a Fairmount tree planting within 1000ft either before or after sales, with other parcels. Columns 1 and 2 suggest that relative to all other sales in Philadelphia, controlling for housing characteristics and seasonal effects as described above, sales price for parcels that were sold within $1000 \mathrm{ft}$ of previous or future Fairmount tree plantings are 2.30 percent higher. Remarkably, this differential does not diminish significantly when those sales are 
compared to sales within $4000 \mathrm{ft}$ of previous or future Fairmount tree plantings and is reduced slightly when compared to sales within $2000 \mathrm{ft}$ of previous or future Fairmount tree plantings (columns 3 to 6). This suggests a baseline, within-tract price differential around 2 percent on average due to unobserved factors correlated to the propensity of ever getting tree plantings within $1000 \mathrm{ft} .^{\text {iii }}$

When the treatment group is defined as all parcel sales that occurred after a Fairmount tree planting within $1000 \mathrm{ft}$, any price differential can be interpreted as either a real change in the quality of the parcel (including the intrinsic value of the trees and promotion of social capital and environmentally conscious behavior), a revelation of its quality (the signaling effect), a third factor effect that coincided with the tree planting (e.g., an exogenous increase in awareness that led to tree plantings and possibly other positive neighborhood changes) or a combination of these. Table 4 presents the results. Relative to all other sales in the same census tract, parcel sales after a Fairmount tree planting within $1000 \mathrm{ft}$ were priced between 9 and 11 percent higher (columns 1 and 2). When compared to other parcel sales that also occurred after a Fairmount tree planting but were further away (2000ft and $4000 \mathrm{ft}$, columns 3 to 6), this effect becomes close to zero and insignificant. This implies that the main factors that drive the 9 to 11 percent price differential work at a level above the immediate neighborhoods. A comparison of parcels with various distances from tree plantings instead of all parcels within the city boundaries by definition controls for all price determinants that are uniform to those parcels. This implies that if the measured impact in columns 1 and 2 were wholly due to third factors other than tree plantings that are common to all parcels within 2000 or 4000 
$\mathrm{ft}$ of the tree plantings, one would also expect the impact to diminish to zero in columns 3 to 6 . However, the measured correlation using an after-planting indicator with prices in Table 4 is substantially higher than the selection bias estimated in Table 3. This supports the idea of a positive and relatively constant tree-related impact on prices within $4000 \mathrm{ft}$.

Compared to the differential found in Table 3, this differential is less likely to be driven by other factors unrelated to tree plantings because those factors would have to coincide with the tree plantings not only in space but also in time. Notably, it is also significantly larger in size. This lends support to the notion that either the tree plantings themselves or the drivers behind the tree plantings (e.g., a signaling motivation) led to price increases.

Table 5 tells a similar story. Here the treatment group consists of the first parcel sales that occurred after a Fairmount tree planting, but not the second or third. In a comparison between the between-sales-planting treatment group and all other sales (again controlling for census tract fixed effect), the price differential is between 9 to 10 percent. This becomes insignificant when the comparison group is limited to sales that also occurred immediately after Fairmount tree plantings but were further away. Because this price differential is tied to the one-time shock of a tree planting, this is even stronger support for price increases that are driven by factors that either resulted from or resulted in tree plantings. 
The intrinsic value of a tree can be expected to affect house prices around a relatively small area. Tables 6 to 8 use a 100ft distance cutoff to explore this. Notably, there is no significant price differential related to the likelihood of ever having a tree planting in close proximity (Table 6). ${ }^{\text {iv }}$ Compared to results in Table 3, this reinforces the idea that the process that generates tree plantings works at a more macro-level. Table 7 , where the treatment group consists of parcel sales after a Fairmount tree planting within 100ft, presents results that are remarkably similar to those using a 1000ft cutoff in Table 4. The only difference is that the price differential as compared to the whole sample (columns 1 and 2) is about 2 percentage points higher. This suggests that the intrinsic value of a tree planting, which is the most likely to vary in strength spatially among the 4 main factors behind the tree-price correlation, is around 2 percent. Again, columns 3 to 6 indicate that the tree-price correlation is largely motivated at a more macro level. The lack of statistical power prevents precise comparisons between the parcels with plantings within 100ft and those with plantings within 500ft to 4000ft directly, but the point estimates in columns 3 to 6 are not far from 2 percent.

Table 8 uses parcel sales with between-sales tree plantings as the treatment group. As argued before, the price differential between this treatment group and other sales is more closely tied to tree plantings than that found in Table 7. Evidence consistent with earlier results is found comparing Tables 7 and 8 . Slightly larger price differentials are identified when we focus on parcel sales with between-sales tree plantings, which diminish both in size and significance when we hold the timing of the planting constant and vary the distance to the plantings. 
To sum up, we find that parcels located within $1000 \mathrm{ft}$ of between-sales Fairmount tree plantings sold at a 9 to 10 percent premium on average. The average premium for parcels within $100 \mathrm{ft}$ of a between-sales planting is 11 to 13 percent. A comparison of these results points to an intrinsic value of a tree planting at around 2 percent. Using all parcel sales after a planting as the treatment group produces very similar results, with slightly smaller point estimates. Remarkably, these price differentials largely diminish when comparing the parcels at different distances but within $4000 \mathrm{ft}$ from the betweensales plantings. A baseline comparison along the propensity to have a tree planting in proximity, using all parcels that have ever had plantings within 100ft (or 1000ft) as the treatment group, indicates that omitted variable bias is around 2 percent. ${ }^{\mathrm{v}} \mathrm{We}$ argue that, after controlling for census tract fixed effects, parcel characteristics and time effects, it is unlikely that the substantial price differentials presented are due to some omitted factors unrelated to tree plantings but somehow coincide with them both in space and time. Therefore we conclude there is a significant price differential related to the tree plantings, between 7 to 11 percent, which is remarkably constant within $4000 \mathrm{ft}$ of the plantings. We posit that this is largely due to social capital (or other positive attitude) creation or a signaling effect, on the top of an intrinsic value of the plantings at around 2 percent.

\section{Empirical Evidence - PHS Plantings}

The main purpose of investigating the PHS tree plantings is to exploit the differences in the application process as compared to the Fairmount plantings. As described in the introduction, PHS plantings involve a much more significant level of 
coordination and cooperation among neighbors in order to obtain a tree planting on the block they live on. If social capital creation were a main driver behind the price differential identified in the previous section, we expect to find an even larger differential looking at PHS plantings. On the other hand, the intrinsic value of trees can be expected to be the same across the programs and both the signaling effect and the omitted variable bias can point in either direction. Equation (1) is estimated as before using PHS plantings. One difficulty of exploring the relationship between PHS plantings and housing prices is the limited number of parcel sales close to the plantings and thus lower statistical power. Table 9 summarizes the results, each row showing the price differential comparing a given treatment group (row) with various control groups (column). In the last six columns the timing of the tree planting is held constant and the only factor that varies between the treatment and control groups is the distance to the planting: the control groups are further away from the plantings. These comparisons give us an idea how localized any treerelated price changes are.

Row 1 confirms that the PHS program target the neighborhoods in need: parcels that have ever had a PHS planting within 1000ft sold at a discount of around 8 percent that remains stable when parcels that have ever had a PHS planting within 2000ft or $4000 \mathrm{ft}$ are used as the control group, implying that the price discount is relatively localized at a $1000 \mathrm{ft}-$ radius. Surprisingly, the parcels that have ever had a PHS planting within 100ft, i.e., those with a higher propensity to request a PHS planting, do not systematically sell at a significant discount (row 2). These together imply that most of the 
homeowners who took advantage of the PHS program in fact own houses of average quality in a below-average neighborhood of a 1000ft radius (about 2 city blocks).

Row 3 shows a price discount between 6 to 11 percent for parcels that were sold after a PHS planting within $1000 \mathrm{ft}$, which is not statistically different from that measured in row 1. Using parcel sales with between-sales tree plantings within $1000 \mathrm{ft}$ produces similar results (row 5). Therefore there is no strong evidence that PHS plantings decreased the negative price differential in a systematic way for parcels within 1000ft and there is unlikely to be significant social capital creation during the process, because this impact is expected to work at a multi-block level. This suggests that the significant price premium identified in the previous section is likely to be due to a signaling effect, where residents request trees from Fairmount Park Commission to signal neighborhood qualities otherwise unobservable to homebuyers.

Any positive impact of the PHS plantings within $100 \mathrm{ft}$ is not precisely measured using this sample (rows 4 and 6). While the point estimates of the price differentials are less negative, there is not enough statistical power for inferences.

\section{Conclusion}

This study makes use of a rich data set with precise location information for all housing sales and tree plantings in Philadelphia between 1998 and 2003. We explore how housing prices evolve around tree plantings. Four main hypotheses are proposed: a positive impact due to the intrinsic value of trees, a positive impact due to generation of social capital, a positive signaling effect and a correlation to unobserved factors of 
ambiguous sign. We attempt to discriminate among these factors by exploiting variations in both timing and geographical locations of tree plantings relative to housing sales. While it is perceivable that the aggregate demand for housing can increase for Philadelphia as a whole because of the newcomers the tree planting programs attract, this city-wide impact is not captured in our analysis.

In addition, we investigate tree plantings through two separate agencies, the Fairmount Park Commission and the Philadelphia Horticultural Society. Because the latter requires a much higher level of coordination among residents, this sheds light on the importance of social capital creation.

For the Fairmount tree program, a 7 to 11 percent price differential is identified. It is a relatively stable effect within $4000 \mathrm{ft}$ of the tree plantings, largely driven by either social capital creation (and attitude changes) or a signaling mechanism. Findings using the PHS tree program suggest that social capital might be a less important channel. Targeting at struggling areas, there is evidence that the PHS tree program was utilized by relatively better-off pockets (with a 1000ft radius) in low-price neighborhoods. Any positive changes brought by the PHS tree plantings were not detected with sufficient statistical power. Therefore we conclude that tree plantings serve as an effective signaling mechanism for home sellers with a small intrinsic value (around 2 percent). Any positive returns from increase in social capital or environmentally-conscious behavior are not apparent in our data. We have left to future research to study larger-scale programs the 
issue of differential impact of the tree programs on neighborhoods by levels of income, environment awareness, demographic composition and other factors. 


\section{Acknowledgements}

We thank Paul Amos for assistance with the Geographical Information Systems, and Steve Ross and Justin Wolfers for detailed comments. We are indebted to the Philadelphia Horticultural Society for providing the tree planting data and much assistance. Eugene Brusilovskiy and Alexandra Infeld provided excellent research assistance. All errors remain ours. Corresponding author: Grace Wong, 1400 SH-DH, 3620 Locust Walk , Philadelphia, PA $19104-6302 \quad+(215) \quad 573 \quad 7903$ wongg@wharton.upenn.edu . 


\section{Reference}

Anderson, L. M., and H. K. Cordell. 1985. Residential Property Values Improve by Landscaping With Trees. Southern Journal of Applied Forestry 9: 162-166. 1988. Influence of Trees on Property Values in Athens, Georgia (USA): A Survey on Actual Sales Prices. Landscape and Urban Planning 15: 153-164.

Getz, D., Karow, A. and J. J. Kielbaso. 1982. Inner City Preferences for Trees and Urban Forestry Programs. Journal of Arboriculture 8: 258-263.

Roback, Jennifer. 1982. Wages, Rents, and the Quality of Life. Journal of Political Economy 90: 1257-1279.

Summit, J. and R. Sommer. 1997. Urban Tree-Planting Programs - A Model for Encouraging Environmentally Protective Behavior. Atmospheric Environment 32: $1-5$. 


\section{Footnotes}

${ }^{\mathrm{i}}$ For example, a tree planting might be a result of the residents' willingness to take care of the environment (positive, reverse causality), a need for cosmetic improvements to a run-down neighborhood (negative, reverse causality), or heterogeneous tastes (either direction, statistical correlation).

${ }^{i i}$ Housing characteristics included in regressions presented in this paper are those that demonstrate a stable and robust relationship with the dependent variable. Adding other controls decreases precision of estimates but does not the main conclusions.

iii In results not shown, comparing before-planting sales of parcels that eventually had a planting within $1000 \mathrm{ft}$ and sales of parcels that never had a planting within $1000 \mathrm{ft}$ gives the same, statistically significant, baseline differential of 2 percent.

${ }^{\text {iv }}$ On average, a city block is one-tenth of a mile, which is $528 \mathrm{ft}$. A tree planting within $100 \mathrm{ft}$ means a tree directly in front of the parcel or its immediate neighbors. In comparison, $4000 \mathrm{ft}$ is about 8 city blocks.

${ }^{\mathrm{v}}$ We acknowledge that this is not a perfect measurement of the omitted variable bias, partly because parcels that have tree plantings in proximity in an out-of-sample year will be wrongly put in the control, instead of the treatment, group. 